\title{
Effect of Nanosilica on the Mechanical Properties, Compression Set, Morphology, Abrasion and Swelling Resistance of Sulphur Cured EPDM/SBR Composites
}

\section{S. Vishvanathperumal}

SA Engineering College

Anand G ( $\sim$ anand.g@pec.edu )

MVJ College of Engineering https://orcid.org/0000-0001-6529-7341

\section{Research Article}

Keywords: EPDM/SBR, silica nanoparticles, mechanical properties

Posted Date: February 24th, 2021

DOl: https://doi.org/10.21203/rs.3.rs-222086/v1

License: (c) (1) This work is licensed under a Creative Commons Attribution 4.0 International License. Read Full License

Version of Record: A version of this preprint was published at Silicon on May 4th, 2021. See the published version at https://doi.org/10.1007/s12633-021-01138-9. 
Effect of nanosilica on the mechanical properties, compression set, morphology, abrasion and swelling resistance of sulphur cured EPDM/SBR composites

\author{
S. Vishvanathperumal ${ }^{1}$, G.Anand ${ }^{2 *}$ \\ ${ }^{1}$ Department of Mechanical Engineering, S.A. Engineering College, Thiruverkadu, Chennai, \\ Tamilnadu, India. \\ ${ }^{2}$ Department of Mechanical Engineering, MVJ College of Engineering, Bangalore, Karnataka, \\ India. \\ *anand.12ng@gmail.com
}

\begin{abstract}
The main objective of the current research work is to explore the effect of nanosilica particles on the compound EPDM/SBR-SiO2 (ethylene-propylene-diene monomer/styrene-butadiene rubbernanosilica). The composite EPDM/SBR with and without silane coupling agent was processed using an open mill mixer. The nanosilica particles are prepared in the laboratory and were used as the reinforcing material in EPDM/SBR rubber composites. The cure characteristics, mechanical properties, hardness, rebound resilience, swelling resistance, abrasion resistance and compression set of the composites are completely analyzed and studied. Nanosilic particles are produced in the laboratory and used as reinforcement material in EPDM/SBR rubber compounds. Fully analyzed and examined are the cure characteristics, mechanical properties, hardness, rebound resilience, swelling resistance, abrasion resistance and compression collection of the composites. It was also evident from the result that with the inclusion of nanosilica particles in the EPDM/SBR rubber composites, the mechanical properties, swelling resistance, hardness, abrasion resistance and compression set properties improved.
\end{abstract}

Keywords: EPDM/SBR; silica nanoparticles; mechanical properties

\title{
1. Introduction
}

Rubber and its blends are commercially used in industries for engineering applications. In particular, the rubber blends exhibits inimitable tailor made properties required for engineering materials. It also decreases the total cost of the product and, to a greater degree, increases its processability[1]. Ethylene propylene diene monomer (EPDM) was a saturated and non-polar rubber with high ozone, weathering and thermal resistance among the various forms of rubber materials. EPDM was generally used in automotive industries and construction industries. Generally, EPDM exhibits a lesser adhesion property but its cost was comparatively at the high side as compared with other rubber compounds. To surmount the shortcomings in EPDM rubber, it was blended with styrene-butadiene rubber (SBR) 
material [2]. There are a broad variety of engineering applications for the EPDM/SBR blend, such as conveyor belts, seals, electrical insulators, gaskets, tires, tubing, etc. [3]. The blended rubber compounds thus ensures higher mechanical properties and abrasion resistance, when it was mixed in the ratio $80: 20$ of EPDM/SBR [4]. These rubber blends are also appropriately used as the matrix material for various industrial and engineering applications. The schematic representation of the EPDM/SBR rubber blends is shown in Figure 1.

\section{Figure 1. Representation of the structure of EPDM/SBR rubber blends}

In recent times, carbon black $(\mathrm{CB})$ and amorphous silica have been widely used to enhance the mechanical properties of rubber blends in the manufacturing of materials [5-7]. Silica has been abundantly present in nature and can easily be extracted from natural agricultural sources such as groundnut shell, bagasse, rice husk, etc. Amongst the different sources of natural silica, rick husk was the most promising one used in the manufacturing of nanosilica. Rice husk was an agricultural biproduct that was abundantly available in rice-producing countries like India, China, and other Asian countries [8]. The removal of rice husk debris was a dreary procedure since it prompts the antagonistic impact to nature such nursery impact during the emanation procedure, air contamination, inhabitance of landfill space and vitality squander, and so forth [9-10]. The preparation of nanosilica from the rice husk therefore reduces the antagonistic ecological effect, furthermore financially helpful considered to industrially accessible silica nanoparticles. The significant elements of rice husk are natural materials (i.e., cellulose and lignin) and hydrated silica; this sort of silica was normally undefined in nature.

The researchers have detailed the various techniques to get ready silica from rice husk debris previously, for example, soluble base and sulfuric corrosive treatment [11], sol-gel strategy [12], calcination process [13] and compound precipitation amalgamation [14]. In this research work, antacid and sulfuric corrosive treatment technique dependent on disintegration process and followed by precipitation process was utilized to extricate silica from the agronomically squander rice husk. The silica got through this method was of high immaculateness with the width of $20-40 \mathrm{~nm}$ in run. Silica nanoparticles are one of the generally utilized as viable strengthening filler in the rubber blends due to its high perspective proportion. The nanofillers utilized in the composite equally used to enhance the different properties of matrix material in nanocomposites. These nanofiller materials are additionally utilized as the adsorbing activators and crosslinking density in the matrix, that guarantees the crosslinking density of the matrix material in addition to the nanofiller materials [15-16].

Due to its prodigious surface property, silica particles are widely used to boost the mechanical properties of the elastic material. The surface bound hydroxyl groups prompts a strong polarity of the material [17]. 
Then again, the poor compatibility with the rubber and interaction between the exceptionally polar filler (nanosilica) and non-polar (like EPDM/SBR, NR/SBR, EPDM/NR, and so on.) rubber matrix was unacceptable for achieving wanted fortifying reinforcing effectiveness [18]. Henceforth, the surface of nanosilica should be changed by silane coupling agent (SCA) which will in general improve the increases the rubber compatibility and interaction among filler and rubber compound which finally leads in the improvement of the mechanical properties of rubber composites [19]. As the surface-topping specialist for nanosilica and as the vulcanizing agent for rubber matrix blend, bis[3-(triethoxysilyl)propyl]tetrasulphide (Si-69) can be used effectively by different SCAs. It offered the unique significance for rubber reinforcement [20-21].

\section{Experimental}

\subsection{Materials}

Styrene butadiene rubber (SBR-1502) and elastic ethylene propylene diene (EPDM KEP 270), 68 percent ethylene content, 4.5 percent termonomer content (ethylidene norbornene) 4.5 percent, 0.86 g/cm3 density was procured from Arihant Reclamation Private Limited, New Delhi. Rice husk was gathered from Bahour, Puducherry, India. Silica nanoparticles were integrated in our research center by disintegration and precipitation procedure and then stored in desiccators. From Vignesh Chemicals, Ambattur, Chennai, India, the chemicals such as zinc oxide, stearic corrosive, bis[3(triethoxysilyl)propyl]tetrasulphide(Si-69), mercaptobenzothiazyl disulphide (MBTS), tetramethylthiuram disulphide (TMTD) and business grade sulfur were procured for the experimental purpose.

\subsection{Preparation of Nanosilica}

In the hot plate, the rice husk was processed so as to expel the dampness present in it. After that, it was steadily and uninterruptedly heated up to $900{ }^{\circ} \mathrm{C}$ for seven hours in a heater and the rice husk debris was collected in a measuring glass. The ash obtained from the rice husk was used to prepare nanosilica through a different processes (disintegration procedure and precipitation process). At first, the collected rice husk ash was mainly dissolved (made of $1 \mathrm{~mol}$ of sodium hydroxide $(\mathrm{NaOH})$ response) in the alkaline medium to break down the carbon - based materials present in it. In this way, the acquired sodium silicate arrangement ( $\mathrm{Na} 2 \mathrm{SiO} 3)$ was washed (sifted) and desiccated in the oven for $24 \mathrm{~h}$ at 100 degree celcius for the dampness material present in it to be removed. At that point, silica precipitation from the sodium silicate solution ( $\mathrm{Na} 2 \mathrm{SiO} 3)$ was treated with 6 mol of sulphuric acid (H2SO4) at a pH of 7 for 24 hours. The silica precipitate was centrifuged and then cleaned in warm water. At $80{ }^{\circ} \mathrm{C}$ for $24 \mathrm{~h}$, 
the last particles present in it are dried and the silica particles are removed from the rice husk [22]. Dissolution Process

$$
\mathrm{SiO}_{2}+2 \mathrm{NaOH} \quad \mathrm{Na}_{2} \mathrm{SiO}_{3}+\mathrm{H}_{2} \mathrm{O}
$$

\section{Precipitation Process}

$$
\mathrm{Na}_{2} \mathrm{SiO}_{3}+\mathrm{H}_{2} \mathrm{SO}_{4} \quad--\longrightarrow \quad \mathrm{SiO}_{2}+\mathrm{Na}_{2} \mathrm{SO}_{4}+\mathrm{H}_{2} \mathrm{O}
$$

\subsection{Composite Preparation}

Table 1 tabulates the composition of the prepared EPDM/SBR rubber composites. In a two-roll open mixing mill with an operating temperature of $80 \mathrm{oC}$, compounding of the material was achieved. The EPDM was fully mixed with SBR and the necessary amounts of nanosilica, Si-69 and curatives were then applied to it. Finally, prior to sheeting off, 10 end-move passes were made. Before the vulcanization process, the aggravated rubber compound was left over overnight for several periods. The vulcanization procedure was performed at the ideal fix time in a semi-robotic water-driven press at $160 \mathrm{oC}$ under a voltage of $30 \mathrm{MPa}$ and a composite rubber sheet of $15 \mathrm{~cm}$ x $15 \mathrm{~cm}$ x $0.2 \mathrm{~cm}$ was made.

\section{Table 1. Formulation for EPDM/SBR-SiO 2 composites}

\subsection{Characterization}

The rheological properties of the rubber compounds are tested by the oscillating disc rheometer at $160^{\circ} \mathrm{C}$, oscillation arc $0.5^{\circ}$, and 100 cycles per minute $(1.66 \mathrm{~Hz})$ test conditions in accordance with the ASTM D-2084 standard. The different output characteristics such as minimal torque $\left(\mathrm{M}_{1}\right)$, maximum torque $\left(\mathrm{M}_{\mathrm{h}}\right)$, etc are measured. Using the equation (1) below, CRI was determined.

$$
\text { CRI }\left(\min ^{-1}\right)=\frac{100}{t_{C 90}-t_{S 2}}
$$

Where, $\mathrm{CRI}=$ Cure Rate Index, $\mathrm{t}_{\mathrm{C} 90}=$ Optimum cure time, $\mathrm{t}_{\mathrm{s} 2=}$ Scorch time

The tensile properties of the composite samples were measured (using type-C die) and was tested at a temperature of $23^{\circ} \mathrm{C}$ on a universal testing machine (UTM) with crosshead speed of $500 \mathrm{~mm} / \mathrm{min}$ as per ASTD 412. The tear characteristics are conducted at $23^{\circ} \mathrm{C}$ on un-nicked $90^{\circ}$ angle test-shaped specimens as per ASTM D 624-B standards on a UTM. The hardness was measured in Durometer with Shore A scale (ASTM D 2240). As per ASTM D 2632, the rebound resilience of the composite materials was determined.

The swelling resistance was conducted as per ASTM D471 by immersion technique. The swelling test was performed on various chemical substances such as aromatic, aliphatic and chlorinated hydrocarbons. 
he relative differences in the weight of the rubber compounds shall be assessed before and after immersion in the solvent. The immersed sample was to be kept at the dark room for 3 days and then to be taken away and cleaned for the removal of excess solvent over the surface, then weighed immediately in the precision weighing balance. The mole percent absorption of Qt for solvent was calculated by using the equation (2) shown below.

$$
Q_{t}(m o l \%)=\frac{\left(M_{f}-M_{i}\right) / W}{M_{0}} \times 100
$$

where, $M_{f}=$ Final mass of the rubber compound, $M_{i}=$ initial mass of the rubber compound $\mathrm{W}=$ Molecular weight of the solvent.

The following equation estimated the amount of crosslinking density (3) [23-25]:

$$
\vartheta\left(\frac{m o l}{c m^{3}}\right)=\frac{1}{2 M_{c}}
$$

where, $\mathrm{M}_{\mathrm{c}}=$ Molar mass between crosslinks.

The molar mass was determined from the Flory-Rehner equation (4) shown below between the crosslinks of the composites [23-26]:

$$
M_{c}\left(\frac{g}{m o l}\right)=\frac{-\rho_{p} V_{s} V_{r}^{1 / 3}}{\ln \left(1-V_{r}\right)+V_{r}+\chi V_{r}^{2}}
$$

where, $\rho_{\mathrm{p}}=$ Density of the material, $\mathrm{V}_{\mathrm{s}}=$ Molar volume of the solvent, $\mathrm{V}_{\mathrm{r}}=$ Volume fraction of polymer in the solvent-swollen filled compound, $\chi$ constant (0.3) [27], and The following equation can be used to measure $\operatorname{Vr}(5)$ [28]:

$$
V_{r}=\frac{1}{1+Q_{m}}
$$

where, $\mathrm{Q}_{\mathrm{m}}=$ Weight swell of the composites in toluene.

The abrasion resistance of the rubber samples is measured according to ASTM D5963 in a DIN abrader. Using the following equation the abrasion loss of the rubber samples are determined (6):

$$
\text { Abrasion loss }\left(\mathrm{mm}^{3}\right)=\frac{\Delta m \times S_{0}}{\rho \times S}
$$

where, $\Delta \mathrm{m}=$ Mass loss in $\mathrm{mg} ; \rho=$ density in $\mathrm{mg} / \mathrm{mm}^{3} ; \mathrm{S}_{0}=$ Nominal abrasive power $(200 \mathrm{mg})$; and $\mathrm{S}=$ Average abrasive power in $\mathrm{mg}$.

The compression set test was performed in accordance with ASTM D395. The compression set was determined using formula shown in equation (7) below:

$$
\text { Percentage of compression set }(\%)=\frac{t_{0}-t_{1}}{t_{0}-t_{s}} \times 100
$$

where, $t_{\mathrm{o}}=$ Original thickness, $\mathrm{t}_{\mathrm{l}}=$ Final thickness and $\mathrm{t}_{\mathrm{s}}=$ Thickness of the spacer bar.

The FESEM was used to analysis the fractured composite specimen surfaces in Hitachi model S4160. The fractured samples were coated with gold layer prior to FESEM examination and the micrograph are taken at $3 \mathrm{kV}$ acceleration voltage. 


\section{Results and Discussions}

\subsection{Rheometric Characteristics}

The cure characteristics, such as minimum torque $\left(\mathrm{M}_{1}\right)$, maximum torque $\left(\mathrm{M}_{\mathrm{h}}\right)$, delta torque $(\Delta \mathrm{M}$ $=\mathrm{M}_{\mathrm{H}}-\mathrm{M}_{\mathrm{L}}$ ), scorch time $\left(\mathrm{t}_{\mathrm{S} 2}\right)$, optimum cure time $\left(\mathrm{t}_{\mathrm{C} 90}\right)$ and cure rate index (CRI) for different compounds are clearly shown in Figure 2 (a-f). The cure characteristics of EPDM/SBR composites are affected by the concentration of the filler and its surface properties[39]. Figure 2 (a-c) represents the minimum torque, maximum torque and delta torque of the nanosilica reinforced EPDM/SBR composites. With an increase in nanosilica loading, the minimum torque, maximum torque and delta torque of EPDM/SBR composites have been found to increase. This was due to the silica nanoparticles' adsorption of curatives[30]. The minimum torque value was expressed by the nanosilica dispersion and the processing characteristics of the composites of EPDM/SBR. The composite of EPDM/SBR has the maximum for minimum torque due to the increasing agglomerates of nanosilica. But, adding of silane couping agent, the minimum torque of composites decreased noticeably to a greater extent. The maximum torque of silane coupling agent composites is much higher than that of silane coupling agent-free composites, which may be due to the breakdown of agglomerates by silane coupling agent. The delta torque indicates that the cross-linking amid the reinforcing material and the matrix. The interactions at the nanosilica-EPDM/SBR interface are higher with the silane coupling agent.

(a) Minimum torque versus Nanosilica Loading

(b) Maximum torque versus Nanosilica Loading

(c) Delta torque versus Nanosilica Loading

(d) Scorch time versus Nanosilica Loading

(e) Optimum cure time versus Nanosilica Loading

\section{(f) Cure rate index versus Nanosilica Loading}

\section{Figure 2. Cure characteristics versus Nanosilica Loading with and without silane coupling agent}

Figure 2 (d-f) shows the graph of the nanosilica-filled EPDM/SBR composites for scorch time, optimum cure time and cure rate index. The scorch time and optimum cure time can be used to estimate the vulcanization rate of the composite. As the concentration of nanosilica increases, the scorch time and optimum cure time of the composites decreases. This was due to the ethoxy-groups present in it and reacts with the surface of nanosilica. In addition, the reduction in scorch time and optimum cure time was due to 
the strong polar interplay of nanosilica with $\mathrm{ZnO}_{2}$ during the process of vulcanization and the forming of $\mathrm{ZnO}_{2}$ bound nanosilica. This decreases $\mathrm{ZnO}_{2}$ activity in order to increase the accelerator during the vulcanization process[31]. The nanosilica filled EPDM/SBR composite cure rate index increases with increased nanosilica concentration. This was due to the effects of silane and ethoxy groups that react effectively on the surface of nanosilica with the hydroxyl group. With the presence of silane coupling agent, scorch time, optimal cure time decreases and the cure rate index rises for the composites. This confirms that the crosslinking among nanosilica and the matrix is on the higher side in comparison.

\subsection{Mechanical properties}

For the optimum cure time, the compounds are vulcanized and the procedure is carried out in the vulcanizing press, and their mechanical properties are studied. The mechanical properties are represented in Figure 3 (a-d). The tensile strength of EPDM/SBRcomposites was shown in Figure 3 (a). With an increase in the nanosilica material concentration of up to $6 \mathrm{phr}$, the tensile strength of the EPDM/SBR composites increases and then decreases gradually. This may be due to the poor interaction of nanosilicaEPDM/SBR caused by the hydrophilic nature of silica nanoparticles that leads to higher loading conditions in the formation of aggregates. In the EPDM/SBR matrix with more agglomerates, nanosilica (without silane coupling agent) was non-uniformly distributed due to the formation of hydrogen bonds between the silanol groups and the nanosilica surface. In comparison with composites without silane coupling agent, the composites containing silane coupling agent show an 18 percent improvement in tensile strength and an increase to 134 percent compared to wit. Most of the silanol groups on the nanosilica surface react with silica nanoparticles to be compatible with the EPDM/SBR and get well distributed in it due to the improvement in the tensile strength due to the incorporation of silane coupling agent. In Figure 3 (b) and (c), respectively, elongation at break and 100\% modulus of EPDM/SBR composites were shown. Break elongation and 100 percent modulus increase with an increase of up to 6

phr in nanosilic loading further reduces with an increment in the loading of EPDM/SBR composites. The increase in break elongation suggests a good interfacial adhesion of the filler-rubber and proper wetting of the nanosilica. The reduction in the elongation at break indicates the restriction of movement in polymeric molecular chains. $100 \%$ modulus was influenced by concentration of the nanosilica loading and the particle size in the EPDM/SBR composites. The composites with SCA shows 5\% decrement in elongation at break and $4 \%$ rise in $100 \%$ modulus compared to that of composite without SCA. The composites with SCA shows $16 \%$ and $51 \%$ increase in elongation at break and $100 \%$ modulus, respectively as related to the neat rubber. Tear strength the rubber composites was shown in Figure 3 (d). Tear strength of the composite rubber steps up with an increasing concentration of nanosilica in the matrix. The tear strength 
of the composite with SCA was higher than that of the composite without SCA. This was due to the rise in the crosslink density of the rubber composite.

(a) Tensile strength versus Nanosilica Loading

(b) Elongation at break versus Nanosilica Loading

(c) $100 \%$ modulus versus Nanosilica Loading

(d) Tear strength versus Nanosilica Loading

Figure 3. Mechanical properties of the composites versus Nanosilica Loading with and without silane coupling agent

\subsection{Hardness and rebound resilience}

The hardness of the composites with respect to the loading of nanosilica has been shown in Figure 4. The composite hardness increases with an increase in initial amount of nanosilica. The composite with SCA indicates that the increase in hardness was due to improved crosslink density and enhanced silica dispersion. Higher crosslinking density was the reason the enhanced hardness. As the composite's crosslink density increased, the softer matrix turns to a harder one. The rebound resilience of the composites was shown in Figure 5. The rebound resilience drops with an increase in concentration of nanosilica, which also improves the rigidity and stiffness of the composites. The composite's rebound resistance was inversely proportional to the material's hardness, thus decreasing with an increase in the nanosilica content. By adding nanosilica, the decrease in rebound resistance was attributed to an improvement in the reinforcing effect[32]. Decreased tendency of rebound resilience may be attributed to improved interaction between matrix and reinforcement. EPDM/SBR composites with and without SCA rebound resistance are comparative. As the content of nanosilica increases in the matrix material, the elasticity of the rubber chains decreases, leading to poor rebound resilience[20]. The rebound resilience of the composite reduces by converting the energy consumed to heat. Generally, the resilience of the composite was inversely proportional to the heat generated during the process.

Figure 4. Hardness of the EPDM/SBR-SiO 2 composites with and without SCA

Figure 5. Rebound resilience of the EPDM/SBR-SiO 2 composites with and without SCA

\subsection{Abrasion resistance}


Abrasion resistance was quite crucial when considering the operational life of the rubber material and was analyzed as volume loss during the DIN test[34]. In Figure 6, the abrasion loss of the composites was shown. The resistance to abrasion of composites increases with the rise in nanosilica concentration. The abrasion resistance of composites with silane coupling agent was obviously greater than that of composites without SCA at the given nanosilica loading point. Improved abrasion resistance properties could be due to improved nanosilica dispersion in the EPDM/SBR matrix. As the reinforcement material, nanosilica has a stronger interfacial relationship with the EPDM/SBR matrix and the reduction of abrasion loss in the EPDM/SBR composites was clearly evident.

\section{Figure 6. Abrasion loss Vs Nanosilica Loading}

\subsection{Compression Test}

Table 2 shows the compression set values of the composites. It is evident from Table 2 that the compression set is poor in the case of neat rubber, while the compression set increases concurrently with the rise in nanosilica concentration. Even after removal of the applied load, the mobility of the rubber chain was limited as the composite module increased. As the concentration of nanosilica increases, the compression set and cross-link density of the composite increase, while the mobility of the polymer chains decreases, causing composite stiffness. As expected, the rise in crosslinking density results in a set value of high compression. For EPDM/SBR-SiO2 composites with the presence of SCA, the crosslinking density was slightly increased compared to composites without SCA. As time and temperature rises, the compression set percentage also rises, and Table 2 shows it clearly. The temperatures have a significant influence on the rubber material's compression set property. The worst retainable elastic properties of the rubber composite material are indicated by the higher compression set. The lower the compression set percentage, the more the engineering composite material is used.

\section{Table 2. Compression set for EPDM/SBR-SiO 2 composites}

\subsection{Swelling properties}

The composites' swelling behavior was affected by the form of matrix, filler, filler geometry (size, shape, orientation, distribution and concentration), solvent and matrix reaction, temperature, penetrants, etc. In order to understand the interfacial interaction of the system, the analysis of the swelling characteristics of the composites can therefore be used effectively. Rubbers are mainly used in manufacturing applications and are exposed throughout their lifespan to a range of chemical environments. The effects of nanosilica loading and the existence of the penetrants were studied via EPDM/SBR composites with and without SCA on mole percent absorption. The swelling curves are 
represented as a graph (i.e., composite vs square time root (t1/2) mole percent uptake (Qt)) and are shown in Figure 7-9.

Table 3 shows the swelling properties in terms of mole percent uptake at different nanosilica loading in hybrid composites with and without SCA for different penetrants. The penetrants used are aromatic such as benzene, toluene, etc., aliphatic materials such as n-petane, n-hexane, etc., and chlorinated chemicals such as dichloromethane, chloroform, etc. The mole-percentage absorption of benzene by nanosilica loading is clearly shown in Figure 7. As nanosilica concentration increases, the mole percent absorption of nanosilica filled EPDM/SBR composites with and without silane coupling agent decreases. With the rise in nanosilica loading, the improvement in mole percent absorption of both EPDM/SBR composites could be explained as a significance of the current pressure involved between the rubber polymeric chain network and the penetrant that acts to shrink the rubber chain network. In fact, with an increase in nanosilica concentration, the crosslinking density in rubber composites increases dramatically, resulting in an increase in network elasticity. In addition, crosslinks restrict the swellinginduced extensibility of the rubber polymeric chains (i.e., macromolecular chains) and make it more difficult for solvent (penetrant) to disperse in the gaps between rubber content molecules and reduce the swelling percentage[35-37], thus combating the dissolution tendency[38As a result, the swelling decreases with network augmentation. It was evident from Table 3 that the swelling properties of EPDM/SBR-SiO2 composites with SCA were comparatively lower than those of a composite without SCA for similar nanosilica loading. This was due to the higher crosslinking density of EPDM/SBR-SiO2 composites with SCA compared to those composites without SCA. Thus, as seen in Table 3, a similar pattern was achieved with aromatic, aliphatic and chlorinated solvent.

\section{Figure 7. Mole percent uptake (mol \%) Vs Time (min)}

\section{Figure 8. Figure 8. Mole percent uptake of pentane, hexane, heptane and octane Vs Time (min)}

\section{Figure 9. Mole percent uptake Vs Time (min) with and without SCA and crosslinked with mixed systems}

The effect of penetrating size on the mole percent uptake of peroxide-crosslinked EPDM/SBR composites filled with pentane, hexane, heptane and octane through $10 \mathrm{phr}$ nanosilica is presented in Figure 8. The higher solvent molecular weight shows the lowest mole percentage uptake, while the lower solvent molecular weight shows the higher mole percentage uptake for the hybrid composite. From Table 3, it was evident that the pattern was as follows: a) aromatic: mesitylene $<$ xylene $<$ Toluene $<$ Benzene b) aliphatic: $\mathrm{n}$-octane $<\mathrm{n}$-heptane $<\mathrm{n}$-hexane $<\mathrm{n}$-pentane c) chlorinated: carbon tetrachloride < chloroform 
$<$ dichloromethane. Thus, both the penetrating solvent and the molecular mass are inversely proportional to each other. Finally, greater composite swelling suggests that it was not best suited to be used in industrial applications. The effect of the SCA on the mole \% uptake of dichloromethane through $10 \mathrm{phr}$ nanosilic-filled EPDM/SBR composites interlinked with mixed systems is shown in Figure 9. Therefore, EPDM/SBR-SiO2 composites with higher nanosilica loading and SCA were practically preferable to SCA-free composites for industrial applications.

Table 3. Mole percent uptake for different penetrant of hybrid composites material

\subsection{Crosslinking density}

The crosslinking density values for EPDM/SBR-SiO2 composites are shown in Figure 10. The crosslinking density was calculated using the swelling data. As the volume of nanosilica content increases, the composite cross-linking density increases. The larger the crosslinking density was mainly accountable for enhanced mechanical properties, durability, swelling and abrasion resistance.

\section{Figure 10. Crosslinking density Vs Nonosilica Loading}

\subsection{Morphology}

The ultimate properties of EPDM/SBR composites are determined by the dispersion of nanofillers in the rubber matrix. Uniform dispersion of nanofillers enhances the properties of the composite. The aggregated nanofillers develop a stress concentration point which results in drop down of properties in the composite materials [39]. As shown in Figure 11(a), the tensile fractured surface of EPDM/SBR-SiO composites clearly indicates the undulations and little roughness with slight agglomerates of silica nanoparticles. The figure 11(b) shows the EPDM/SBR-SiO ${ }_{2}$ composites with silane coupling agent. From figure 11(b) it was clear that irregularity over the fractured surface was observed with undulation. The homogeneous dispersion of silica nanoparticles results in effective load transfer which leads to the improvement in mechanical properties of composites with silane coupling agent.

\section{Figure 11. Figure 11. SEM Micrograph of tensile fractured specimen with the Magnifications: $X=$}

$$
20,000 \text { (a) } \mathrm{S}_{6} \text { and (b) } \mathrm{SS}_{6}
$$

\section{Conclusions}

Current investigations have analyzed and reported the cure characteristics, mechanical characteristics, abrasion and swelling resistance of EPDM/SBR-SiO2 composites with and without SCA.

From the experimental findings, the following conclusions were derived: 
(a) The minimum torque and the other related components are increased, whereas the scorch time and optimum cure time decreases with the rise in the weight content of silica nanoparticles in the hybrid composites with and without SCA.

(b) An increase in torque values was achieved for the nanosilica filled composites, that clearly indicates better crosslinks in the system.

(c) The tensile characteristics such as strength, elongation at break, etc., of the hybrid composites steps up with increase in the content of nanosilica up to $6 \mathrm{phr}$ and then again drops.

(d) The addition of nanosilica in the rubber blend enhances the other properties such as tear strength, hardness, swelling and abrasion resistance but at the same time there is a drop in the rebound resilience property of the material.

(e) Whereas, at a similar loading condition of nanosilica, the hybrid composites with SCA clearly indicates a slightly improved mechanical properties, hardness, abrasion and swelling resistance as compared with the composites without silane coupling agent, which was due to the better crosslinking density of EPDM/SBR-SiO ${ }_{2}$ composites with silane coupling agent.

\section{Funding statement}

Not applicable

\section{Conflict of Interest}

The authors declare no conflict of interest.

\section{Author contributions}

All authors are combined to fabricate the samples, testing conducted and paper preparation.

\section{Availability of data and material}

All data generated or analyzed during this investigation are included in this published article.

\section{Compliance with ethical standards}

No, all testing are conducted in this study as per ASTM standards.

\section{Consent to participate}

The authors declare the no objection of consent to participate

\section{Consent for Publication}

The authors declare the no objection of consent to publication

\section{*Acknowledgments}

The author is highly grateful to SA Engineering college, Chennai, India for their kind support in providing the time for research for academic interest. The authors would also like to give appreciation to Dr. Gopalakannan, Professor at Adhiparasakthi Engineering College for his advice and suggestion during preparation of this manuscript.

\section{References:}

1. Monfared A, Jalali-Arani A, Mohammadi N, 2014. The effect of epoxidized natural rubber and two kinds of organoclay upon molecular interaction, structure and mechanical properties of (styrene- 
butadiene rubber/acrylonitrile-butadiene rubber/organoclay) nanocomposites. Journal of Macromolecular Science Part B, 53 (5), 918-930.

2. Dubey KA, Bhardwaj YK, Chaudhari CV, Bhattacharya S, Gupta SK, Sabharwal S, 2006. Radiation effects on SBR-EPDM blends: a correlation with blend morphology. Journal of Polymer Science Part B: Polymer Physics, 44(12), 1676-1689.

3. Zanchet A, Carli LN, Giovanela M, Brandalise RN, Crespo JS,2012.Use of styrene butadiene rubber industrial waste devulcanized by microwave in rubber composites for automotive application. Materials and Design, 39, 437-443.

4. Muraleedharan Nair T, Kumaran MG, Unnikrishnan G,2004.Mechanical and aging properties of crosslinked ethylene propylene diene rubber / styrene butadiene rubber blends. Journal of Applied Polymer Science, 93, 2606-2621.

5. Mark JE, Erman B, Roland M (Eds.), 2013.The Science and Technology of Rubber. Academic Press, United States.

6. Senthilvel K, Vishvanathperumal S, Prabu B, John Baruch L, 2016. Studies on the morphology, cure characteristics and mechanical properties of acrylonitrile butadiene rubber with hybrid filler (carbon black/silica) composite. Polymers and Polymer Composites, 24 (7), 473-480.

7. Vishvanathperumal S, Gopalakannan S, 2016. Reinforcement of Ethylene Vinyl Acetate with Carbon Black/Silica Hybrid Filler Composites. Applied Mechanics and Materials, 852, 16-22.

8. Cago, Lanessa, 2017. 10 Largest Rice Producing Countries, World Atlas, viewed 16 December 2019, <https://www.worldatlas.com/articles/the-countries-producing-the-most-rice-in-the-world.html/>.

9. Chen XG, Lv SS, Zhang PP, Zhang L, Ye Y, 2011.Thermal destruction of rice hull in air and nitrogen.Journal of Thermal Analysis and Calorimetry, 104, 1055-1062.

10. Johar N, Ahmad I, Dufresne A, 2012. Extraction: preparation and characterization of cellulose fibres and nanocrystals from rice husk. Industrial Crops and Products, 37, 93-99.

11. Vaibhav V, Vijayalakshmi U, Mohana Roopan S, 2015.Agricultural waste as a source for the production of silica nanoparticles. Spectrochimica Acta Part A: Molecular and Biomolecular Spectroscopy, 139, 515-520. 
12. Le VH, Thuc CNH, Thuc HH, 2013. Synthesis of silica nanoparticles fromVietnamese rice husk by sol-gel method. Nanoscale Research Letters, 8, 1-10.

13. Ding Y, Su D, 2012. Purifying native in-situ mastoid $\mathrm{SiO}_{2}$ from rice husk. Energy Procedia: Part $\mathrm{B}$ $16,1269-1274$.

14. Ma Y, Zhao X, Zhang H, Wang Z, 2011. Comprehensive utilization of the hydrolyzed productions from rice hull. Industrial Crops and Products, 33, 403-408.

15. Vishvanathperumal S, Navaneethakrishnan V, Gopalakannan S, 2018. The Effect of Nanoclay and Hybrid Filler on Curing Characteristics, Mechanical Properties and Swelling Resistance of EthyleneVinyl Acetate/Styrene Butadiene Rubber Blend Composite. Journal of Advanced Microscopy Research, 13 (4), 469-476

16. Qu L, Yu G, Xie X, Wang L, Li J, Zhao Q, 2013.Effect of silane coupling agent on filler and rubber interaction of silica reinforced solution styrene butadiene rubber. Polymer Composites, 34(10), 15751582.

17. Li Y, Han B, Wen S, Lu Y, Yang H, Zhang L, Liu L, 2014. Effect of the temperature on surface modification of silica and properties of modified silica filled rubber composites. Composites Part A: Applied Science and Manufacturing, 62, 52-59.

18. Gauthier C, Reynaud E, Vassoille R, Stelandre LL, 2004. Analysis of the non-linear viscoelastic behaviour of silica filled styrene butadiene rubber. Polymer, 45(8), 2761-2771.

19. Wolff S, 1996. Chemical aspects of rubber reinforcement by fillers. Rubber Chemistry and Technology,69, 325-45.

20. Vishvanathperumal S, Gopalakannan S, 2019.Effects of the Nanoclay and Crosslinking Systems on the Mechanical Properties of Ethylene-propylene-diene Monomer/styrene Butadiene Rubber Blends Nanocomposite. Silicon, 11(1), 117-135.

21. Vishvanathperumal S, Gopalakannan S, 2017. Swelling properties, compression set behavior and abrasion resistance of ethylene-propylene-diene rubber/styrene butadiene rubber blend nano composites. Polymer Korea, 41(3), 433-442.

22. Vaibhav V, Vijayalakshmi U, Mohana Roopan S,2015.Agricultural waste as a source for the production of silica nanoparticles. Spectrochimica Acta Part A:Molecularand Biomolecular Spectroscopy, 139, 515-520. 
23. Manoj KC, Kumari P, Rajesh C, Unnikrishnan G,2010. Aromatic liquid transport through filled EPDM/NBR blends. Journal of Polymer Research, 17, 1-9.

24. Sujith A, Unnikrishnan G,2006. Molecular sorption by heterogeneous natural rubber/poly(ethyleneco-vinyl acetate) blend systems. Journal of Polymer Research, 13, 171-180.

25. Thomas PC, Tomlal JE, Selvin TP, Thomas S, Joseph K,2010. High-performance nanocomposites based on acrylonitrile butadiene rubber with fillers of different particle size: Mechanical and morphological studies. Polymer Composites 31, 1515-1524.

26. Flory PJ, Rehner J,1943.Statistical Mechanics of Cross-Linked Polymer Networks I. Rubberlike Elasticity. The Journal of Chemical Physics, 11, 512.

27. Naseri ASZ, Arani AJ,2015. A comparison between the effects of gamma radiation and sulfur cure system on the microstructure and crosslink network of (styrene butadiene rubber/ethylene propylene diene monomer) blends in presence of nanoclay. Radiation Physics and Chemistry, 115, 68-74.

28. Noriman NZ, Ismail H,2012. Properties of styrene butadiene rubber (SBR)/recycled acrylonitrile butadiene rubber (NBRr) blends: the effects of carbon black/silica (CB/silica) hybrid filler and silane coupling agent, Si69. Journal of Applied Polymer Science, 124, 19-27.

29.Zhang C, Tang Z, Guo B, Zhang L, 2018.Significantly improved rubber-silica interface via subtly controlling surface chemistry of silica. Composites Science and Technology, 156, 70-77.

30.Ryu C, Kim SJ, Kim D, Kaang S, Seo G, 2016. The Effect of Surface Area of Silicas on Their Reinforcing Performance to Styrene-butadiene Rubber Compounds. Elastomers and Composites, 51, $128-137$.

31.Surya I, Ismail H, Azura AR, 2014. The comparison of alkanol amide and silane coupling agent on the properties of silica- filled natural rubber (SMR-L) compounds. Polymer Testing, 40, 24-32.

32. Peng H, Liu L, Luo Y, Wang X, Jia D, 2009.Effect of 3-Propionylthio-1-propyltrimethoxylsilane on Structure, Mechanical, and Dynamic Mechanical Properties of NR/Silica Composites. Polymer Composites, 30, 955-961.

33. Dileep P, Narayanankutty SK, 2020. Styrenated phenol modified nanosilica for improved thermooxidative and mechanical properties of natural rubber. Polymer Testing. In Press. 
34. Zhang X, Cui H, Song L, Ren H, Wang R, He A, 2018.Elastomer nanocomposites with superior dynamic mechanical properties via trans-1, 4-poly (butadiene-co-isoprene)incorporation. Composites Science and Technology, 158, 156-163.

35. Kader MA, Bhowmick AK, 2003. Thermal ageing, degradation and swelling of acrylate rubber, fluoro rubber and their blends containing poly function alacrylates. Polymer Degradation and Stability, 79, 283-95.

36. Alam MM, Mina MF, Akhtar F, 2003. Swelling and hydration properties of acrylamide hydrogel in distilled water. Polymer-Plastics Technology and Engineering, 42,533-42.

37. Gwaily SE, Badawy MM, Hassan HH, Madani M, 2003. Influence of thermal ageing on crosslinking density of boron carbide/natural rubber composites. Polymer Testing, 22, 3-7.

38. Mostafa A, Kasem AA, Bayoumi MR, El-Sebaie MG, 2009.Effect of carbon black loading on the swelling and compression set behavior of SBR and NBR rubber compounds. Materials and Design, $30,1561-1568$.

39. Zhang H, Gao Y, Li F, Zhang Z, Liu Y, Zhao G, 2016. Influence of silane coupling agents on vulcanized natural rubber: Dynamic properties and heat buildup .Plastics, Rubber and Composites, $45,9-15$. 
Figures

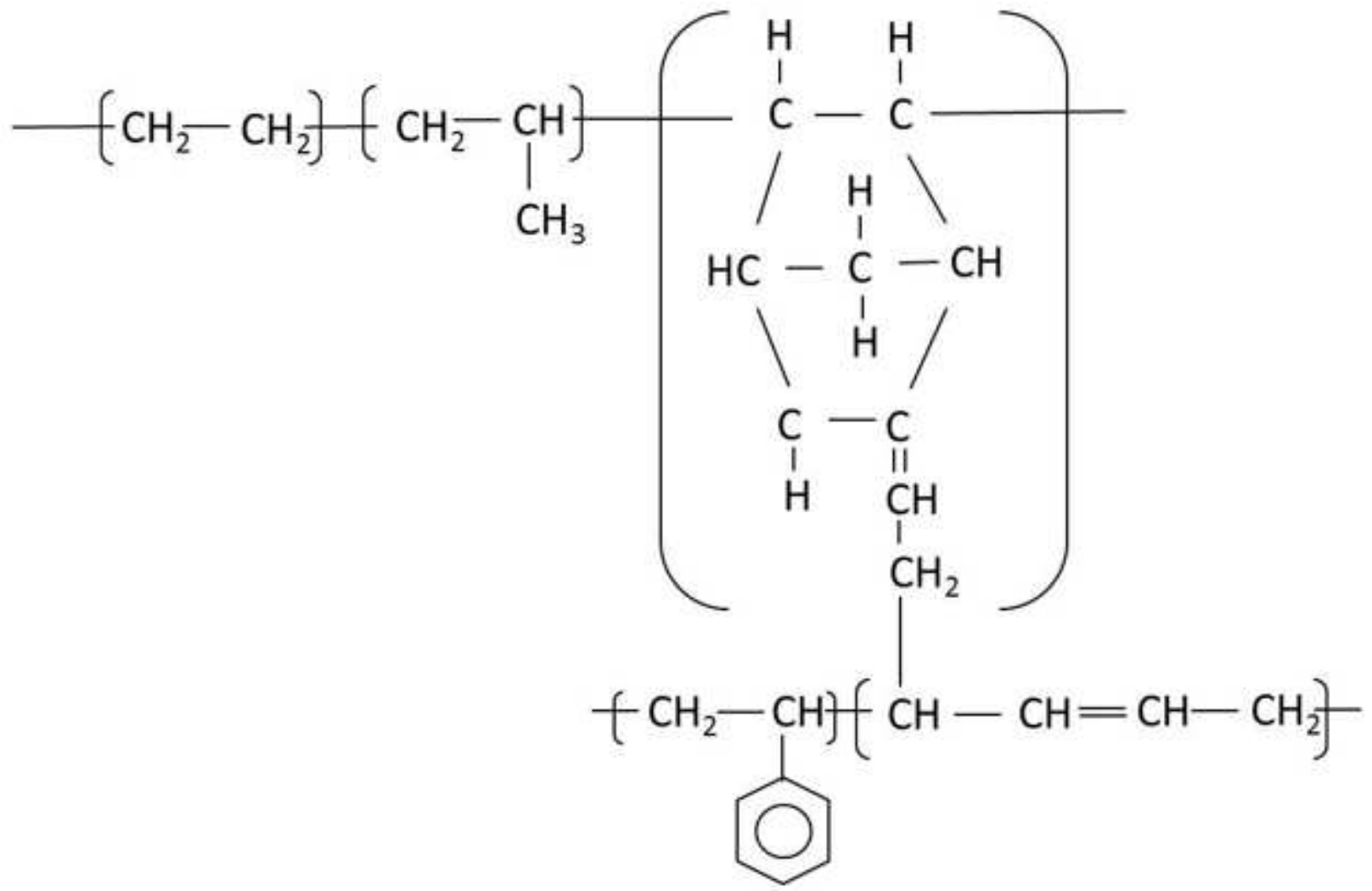

Figure 1

The proposed interaction of EPDM/SBR blends 


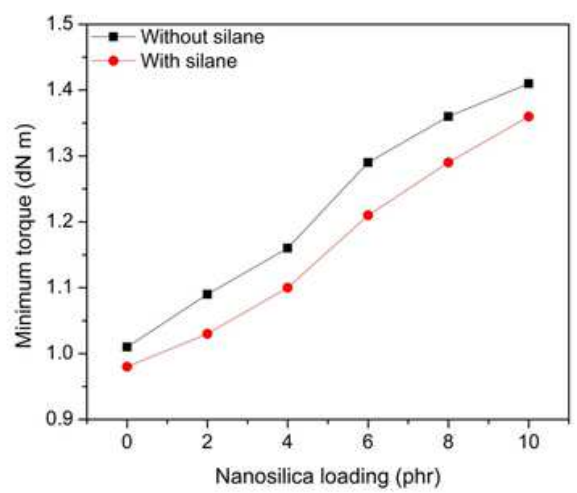

(a) Minimum torque Versus Nanosilica Loading

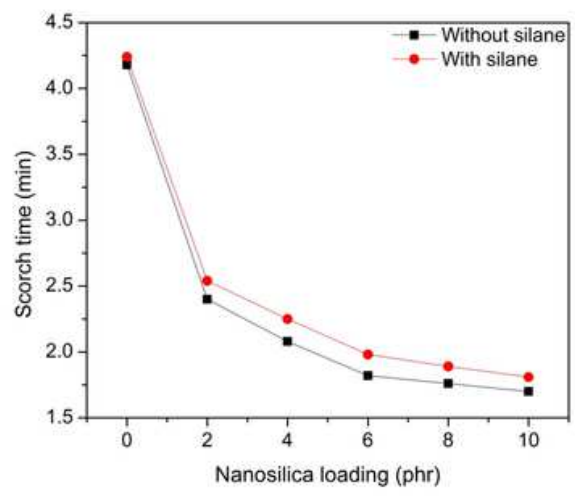

(d) Scorch time versus Nanosilica Loading

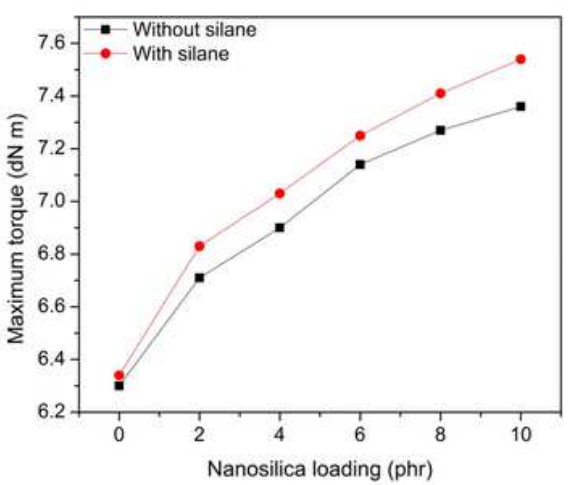

(b) Maximum torque versus Nanosilica Loading

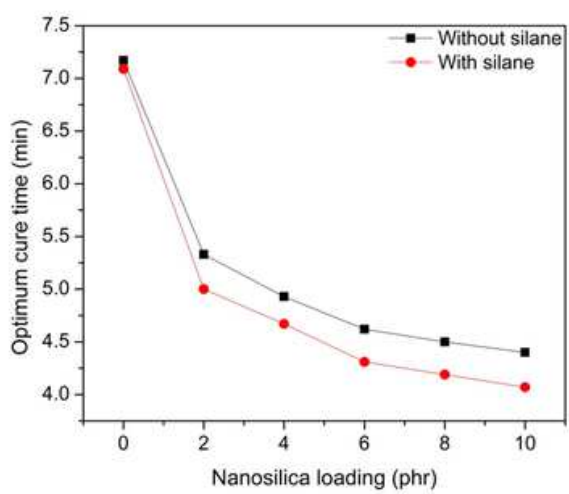

(e) Optimum cure time versus Nanosilica Loading

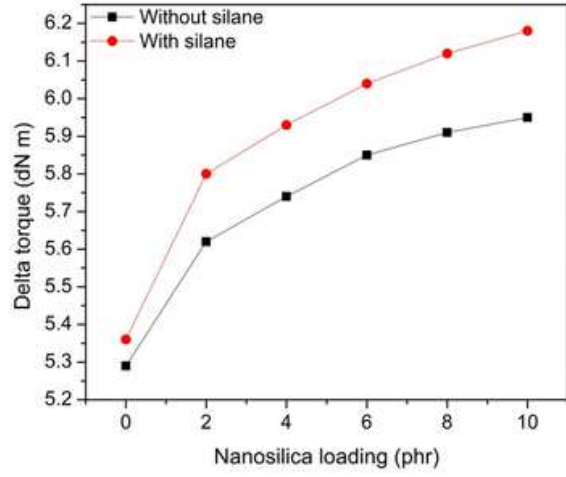

(c) Delta torque versus Nanosilica Loading



(f) Cure rate index versus Nanosilica Loading

\section{Figure 2}

Cure characteristics versus Nanosilica Loading with and without silane coupling agent

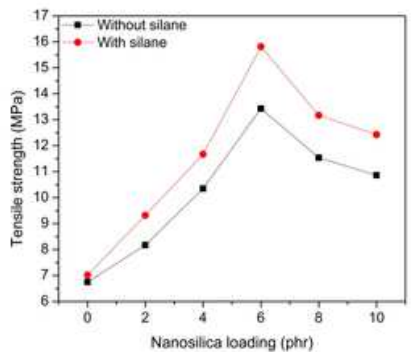

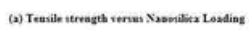



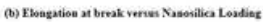

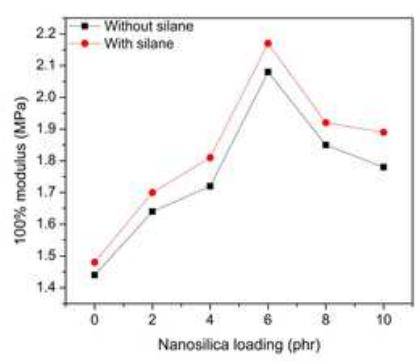

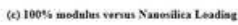

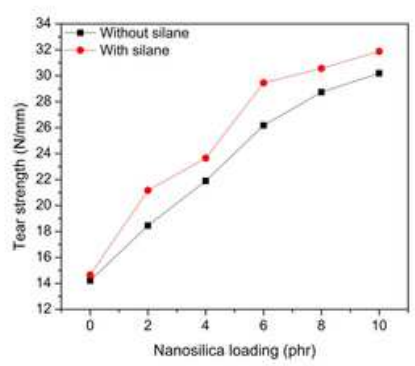

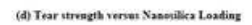

\section{Figure 3}

Mechanical properties of the composites versus Nanosilica Loading with and without silane coupling agent 




Figure 4

Hardness of the EPDM/SBR-SiO2 composites with and without silane coupling agent 


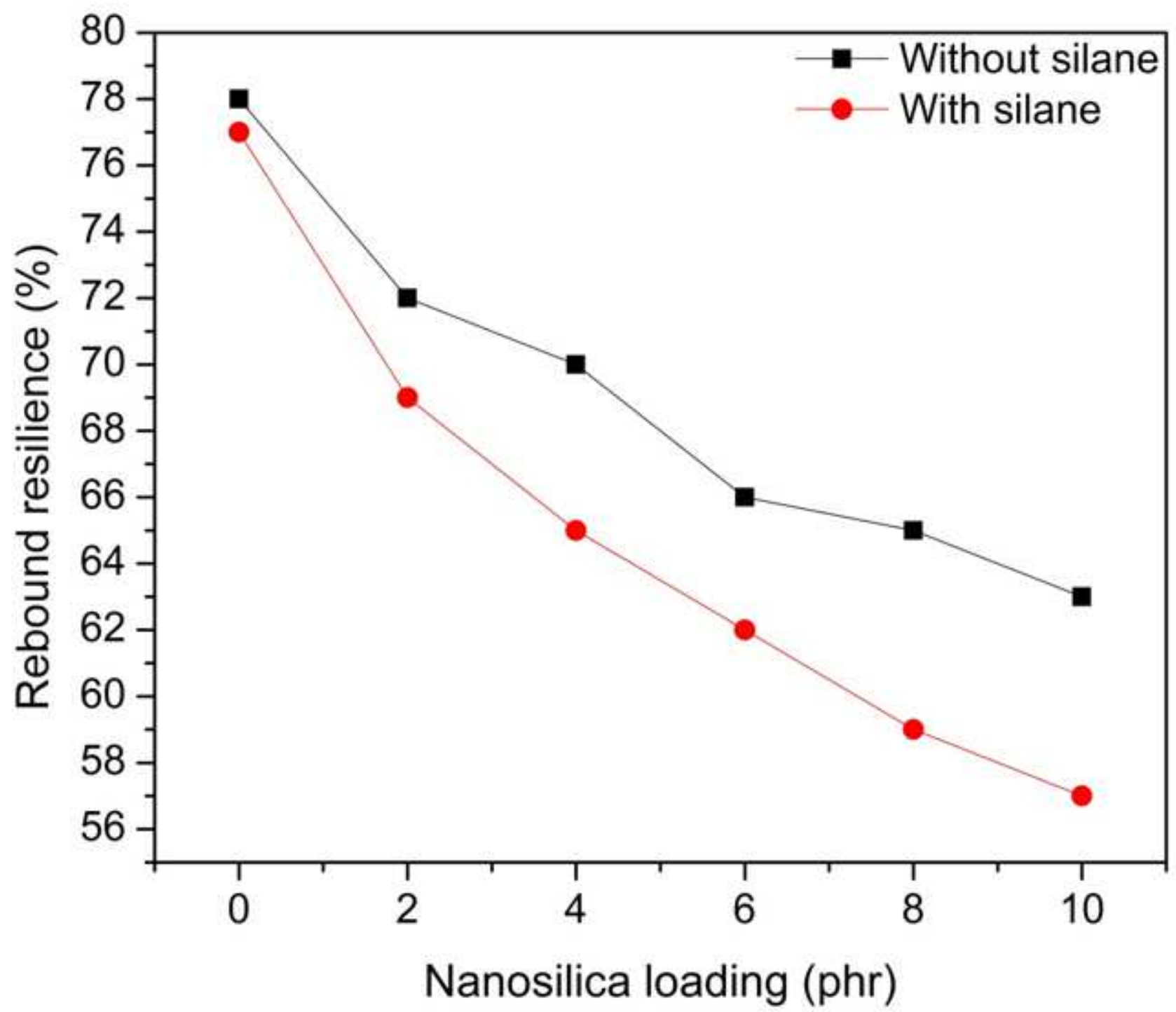

Figure 5

Rebound resilience of the EPDM/SBR-SiO2 composites with and without silane coupling agent 


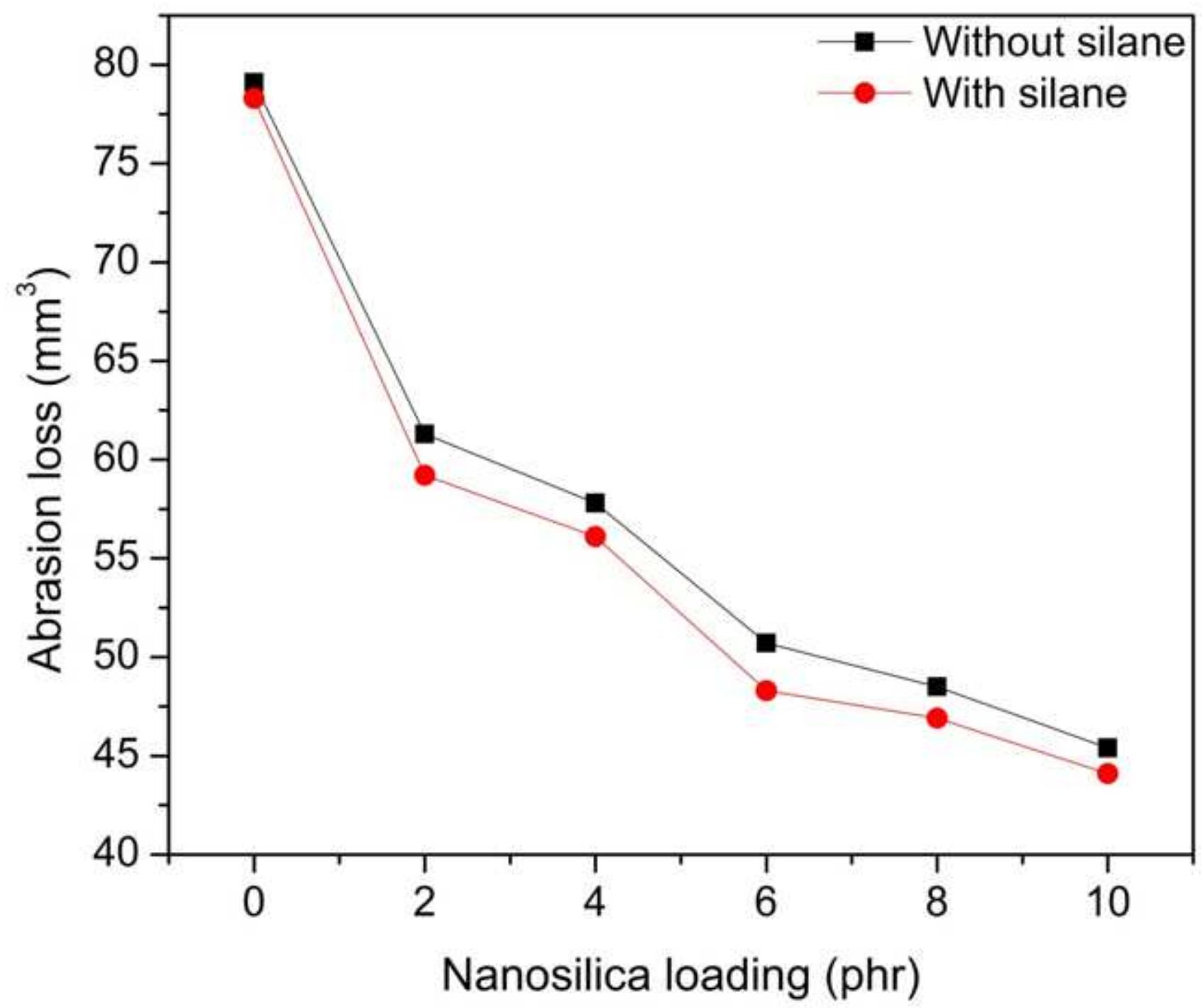

Figure 6

Abrasion loss Vs Nanosilica Loading 


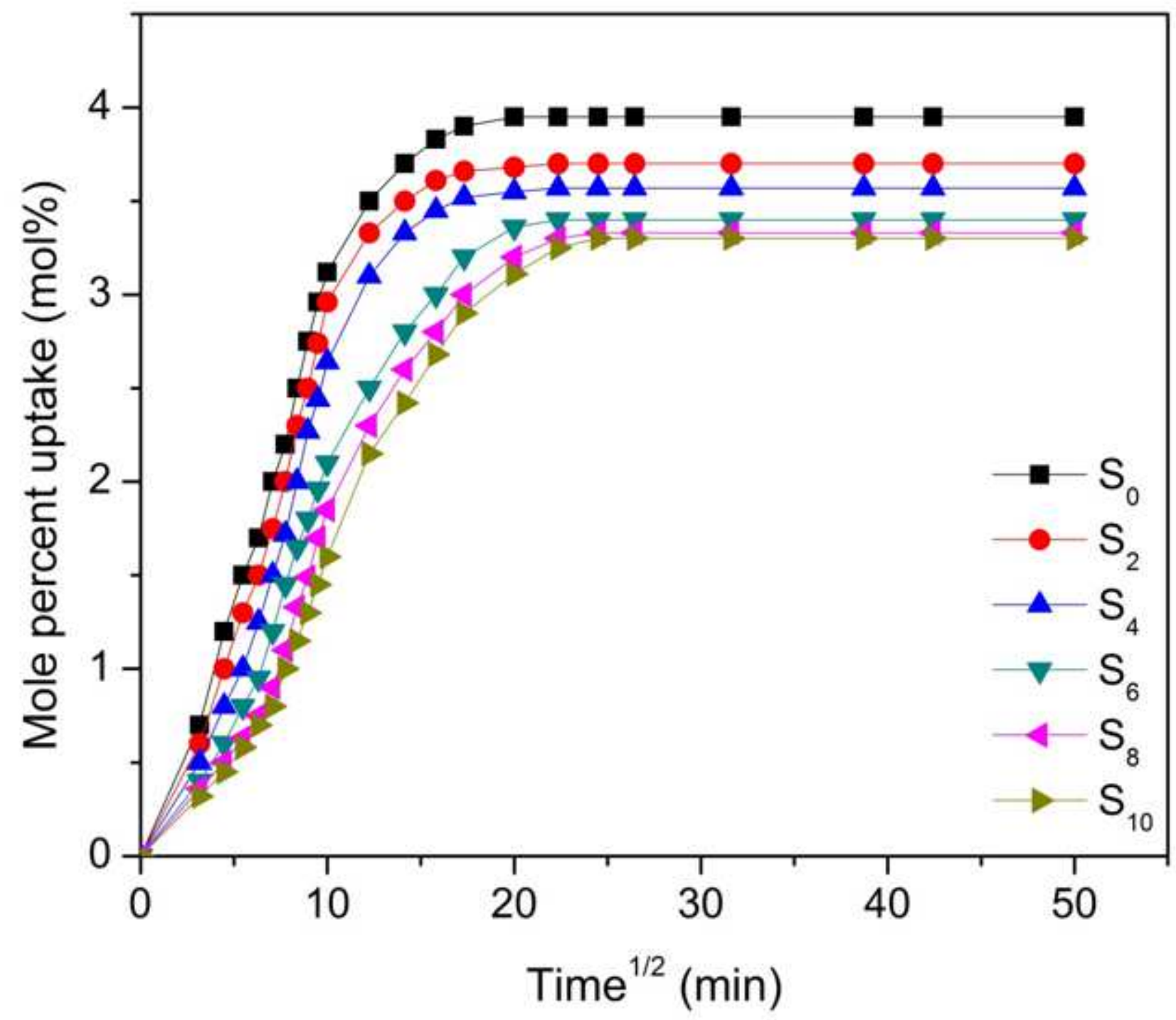

Figure 7

Mole percent uptake (mol \%) Vs Time (min) 




Figure 8

Mole percent uptake of pentane, hexane, heptane and octane Vs Time (min) 


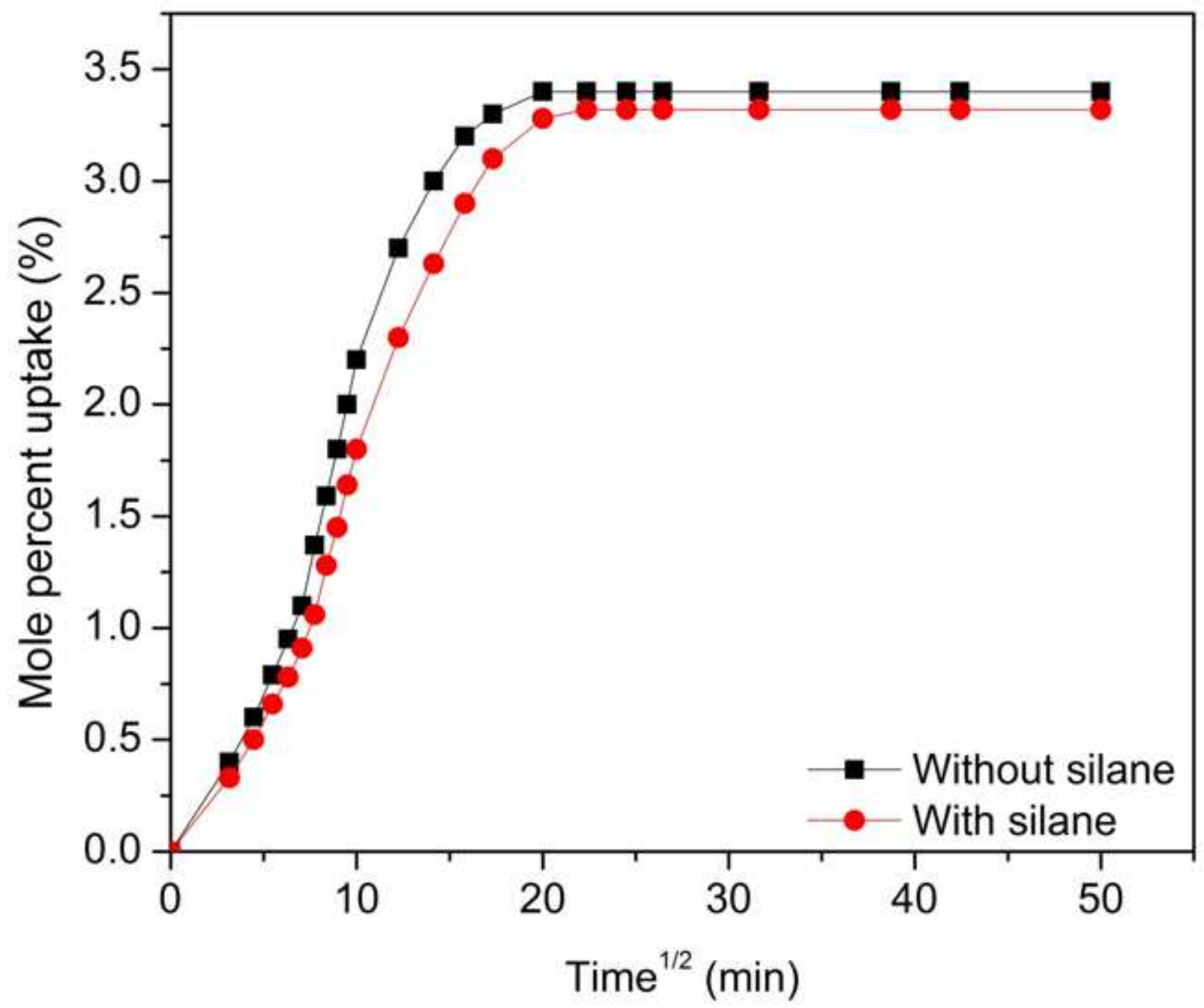

Figure 9

Mole percent uptake Vs Time ( $\mathrm{min}$ ) with and without SCA and crosslinked with mixed systems 


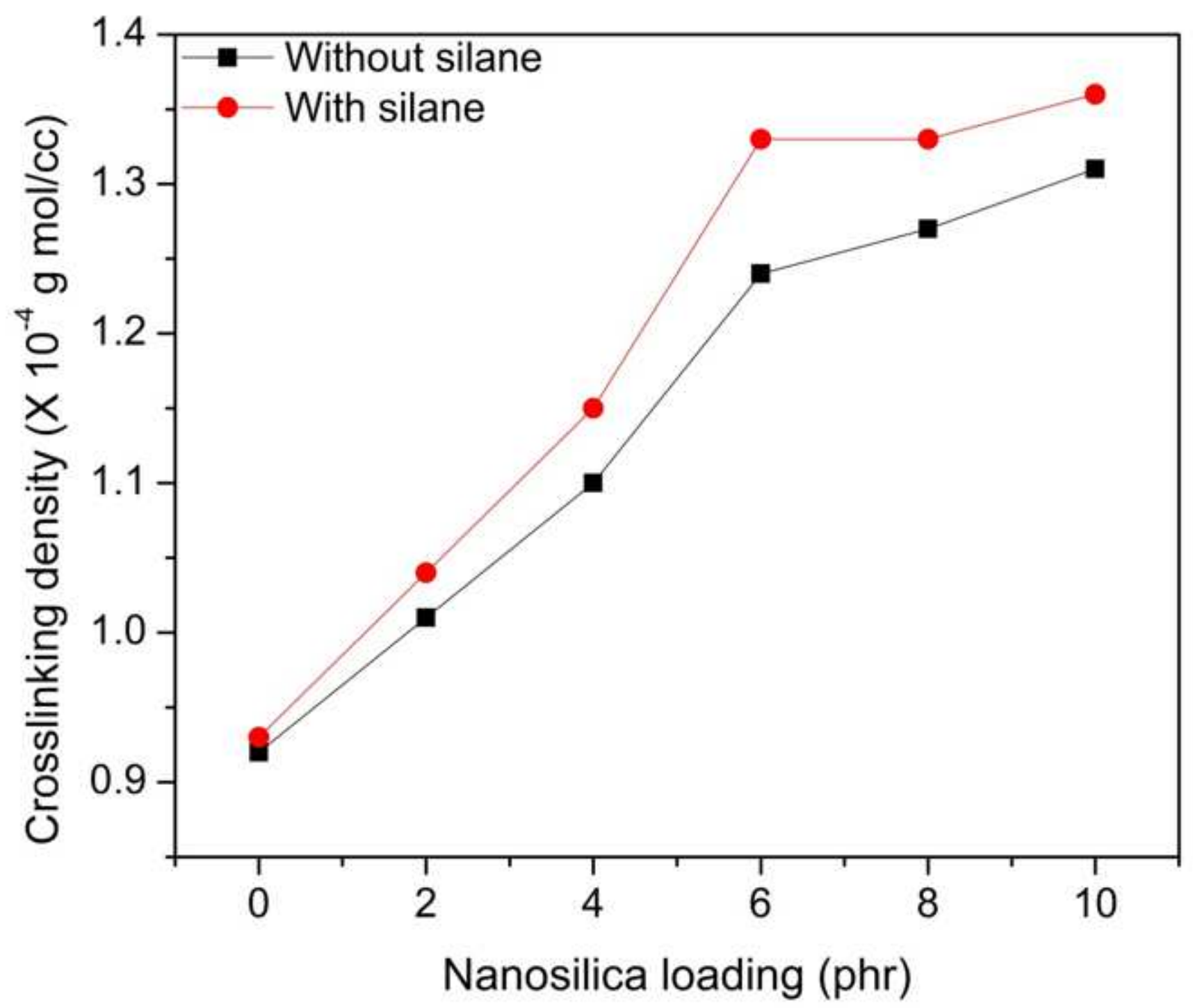

Figure 10

Crosslinking density Vs Nonosilica Loading 

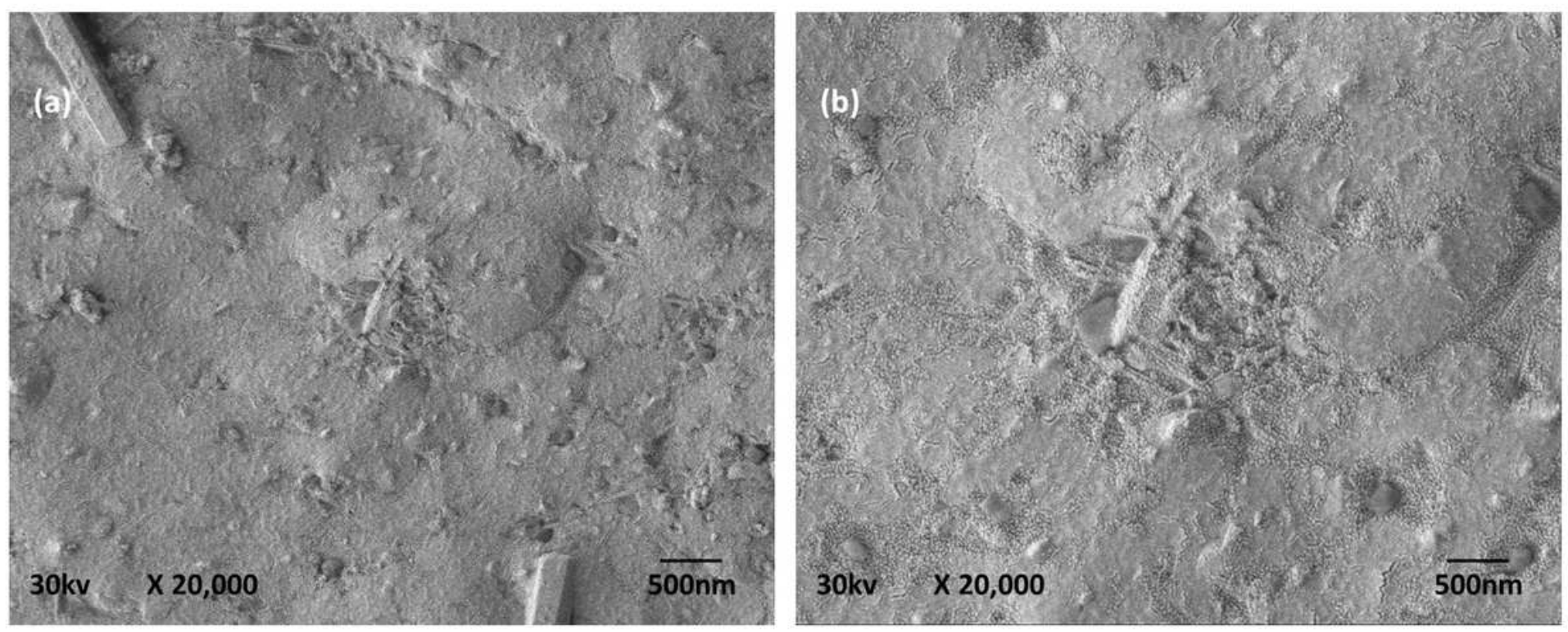

\section{Figure 11}

SEM Micrograph of tensile fractured specimen with the Magnifications: $X=20,000$ (a) S6 and (b) SS6 